A BEAUTIFUL METAPHOR: TRANSFORMATIVE LEARNING THEORY

Peter Howie

Professor Richard Bagnall

Education and Professional Studies

Griffith University

+61411873851

peter.howie@griffithuni.edu.au

Corresponding Author - Peter Howie

June 2013 


\section{Bio notes.}

Peter C Howie is a PhD candidate with Griffith University, Australia, 0411873851.

His research is into the psychodramatic concept of warm-up and he is reconceptualising and evaluating the concept and developing a process for evaluating the goodness of a concept.

Richard G Bagnall is Professor in the Arts, Education and Law academic group, Griffith University, Australia. His work is in the social philosophy of adult and lifelong education and he has published over 100 books and papers in that field. 


\title{
A beautiful metaphor: Transformative learning theory
}

\begin{abstract}
This article presents a critique of both transformative learning theory and critical comments on it to date. It argues that transformative learning theory remains substantively the same as its initial exposition, in spite of a raft of problematic contentions voiced against it. The theory is argued here to be conceptually problematic, except at the level of a conceptual metaphor, which latter renders its many inconsistencies inconsequential, and which explains, not just its continued popularity among educational practitioners, but also its largely being ignored as a subject worthy of serious critique.
\end{abstract}

\section{Introduction}

Mezirow's Transformative Learning Theory is noteworthy to the extent that, over the last 35 years, it has proven to have great staying power as an idea, and to be a prolific producer of offshoots and closely related ideas, while remaining true to its original construction (Mezirow, 2009, 2012; Mezirow and Associates, 2000). What is apparently anomalous about that historical progression, is that it has occurred in spite of many clear and unattended problems with the theory having been highlighted on numerous occasions. This paper seeks to provide a consolidated critique of the theory, drawing on those previously articulated problems, and to argue that the theory's interpretation as a conceptual metaphor serves to explain the apparent anomaly.

Transformative Learning Theory (throughout this paper, Transformative Learning Theory or the theory) was developed and first presented by Mezirow and Marsick in 1978 (Mezirow and Marsick, 1978). A collaboration between Jack 
Mezirow, Victoria Marsick, and others gave birth to the theory, then called perspective transformation, about which Mezirow has written so extensively that it has become 'his' theory. However, it continues as a large-scale collaboration with many practitioners contributing through descriptions of their applications of the theory, and their understandings of it (Mezirow, 1991; Mezirow and Associates, 2000; Mezirow, Taylor, and Associates, 2009; Taylor, Cranton and Associates, 2012). If one considers the number of people utilising the theory in one form or another, for activities such as research and designing learning interventions, it is reasonable to conclude that it continues to remain highly relevant for adult educators (Taylor, 1997, 2000a, 2011). Indeed, it has been celebrated as being the "new andragogy ${ }^{1}$ and as the central adult learning theory of the day by some transformative learning theorists (Cranton and Taylor, 2012, p. 16; Taylor, 2007).

This paper presents an outline of the theory, followed by an overview of critical evaluation of it to date. Then follows an outline of the technical nature of conceptual metaphors and of why the theory can best be understood as a conceptual metaphor. The problematic areas of the theory that provide evidence for such an interpretation are then used as arguments for it. Some implications of viewing the theory as a metaphor are then drawn out, before presenting some concluding comments.

\section{Transformative learning theory}

Transformative learning theory has a number of elements. It begins with a person

\footnotetext{
1 Andragogy (sometimes spelt 'androgogy') is a term that refers to principles of learning focused on adults. It is contrasted with the term 'pedagogy', which is focused on children's learning. It was coined by Knowles (1970) to emphasise the point that there might be different principles for teaching adults, rather than children.
} 
being engaged in activities that cause a disorienting dilemma ${ }^{2}$ leading them to modify or shift one of their meaning schemas or meaning perspectives, which are part of their frame of reference (Mezirow, 1991). The shift may be fast or epochal, or it may be slow or incremental. It may be in the instrumental domain of learning or in the communicative domain of learning. It has an unsteadying influence on the individual's life, with the consequence that the subject seeks to make sense of their experiences. This process is improved by the subject engaging both in their own critical reflection, and with other adults in rational discourse on the area that has shifted. These key terms are explicated below.

The theory describes an adult's assumptions, beliefs, and expectations about the world, as part of a frame of reference through which individuals filter their incoming sense impressions of the world. A person's frame of reference, according to Mezirow (2000, p. 16):

...selectively shapes and delimits perception, cognition, feelings and disposition, by predisposing our intentions, expectations, and purposes. It provides the context for making meaning within which we choose what and how a sensory experience is to be construed and/or appropriated.

In that context, according to Mezirow (2009, p. 22, Mezirow's italics):

Transformative learning may be defined as learning that transforms problematic frames of reference to make them more inclusive, discriminating, reflective, open, and emotionally able to change.

After a transformation in a frame of reference, a person is said to view themselves and their world in a superior manner to that previously, as a result of their assumptions

2 Italics here identify uses common in Transformative Learning Theory writing. 
and expectations having been challenged and modified to better fit their reality or context. Transformative learning is seen as a particular type of adult learning (Mezirow \& Marsick, 1978; Mezirow, 1978, 1991, 2000).

Two further structures are part of a frame of reference: meaning schemas and meaning perspectives (Mezirow, 1991). A meaning schema is said to be constructed of beliefs about how something works, how to do something, how to understand something, someone or a group, or how to understand oneself. A meaning perspective is a more fundamental belief than a meaning schema and is, according to Mezirow (1991, p. 42), a 'structure of assumptions within which one's past experience assimilates and transforms new experience'. Meaning perspective beliefs might include, for example, a notion of a person's legitimate role in the world, the importance of family, or a person's identity. The possibility of transformation in either of these two structures is recognised, although transforming a meaning perspective may be seen as being more far reaching (Mezirow, 2012).

Interpreting Habermas's ideas, Mezirow (1985) developed the concept of domains of learning, and the theory now describes transformations in meaning perspectives as occurring in either the instrumental domain or the communicative domain. The instrumental domain is seen as involving an understanding of how things work, with meaning being created using hypothetico-deductive reasoning and experimental engagement with the environment (Mezirow, 1991, 2012). The communicative domain is seen as involving relationships between people: how people communicate together; how they present themselves; how they understand one another; and generally how beliefs and practises of human communication occur. It is where meaning is created through abductive reasoning, which is seen as the process of using one's own experience to understand another's, and where each step in the chain 
of reasoning suggests the next step (Mezirow, 1991).

The theory suggests that there are two types of transformation in meaning perspective: epochal and incremental (Mezirow, 1991). An epochal transformation is said to occur when a learner's meaning perspective shifts very quickly. An incremental transformation, on the other hand, is the result of small shifts in a meaning schema that, over time, perhaps over months or years, lead a learner to slowly realise that a meaning perspective has shifted.

According to the theory, disorienting dilemmas, critical reflection, and rational discourse are experiences that can bring about transformative learning, with the application or experiencing of one or some combination of these elements leading to transformative learning. Transformative learning may occur in a linear manner, or it may be disjointed, individualistic, fluid, or recursive (Mezirow, 1991; Taylor, 1997, 2000a, p. 292). A disorienting dilemma is said to be a dilemma that causes a significant level of disruption or disturbance in a person, and where their frame of reference is shown to be inadequate to explain what they have seen, heard, or experienced. Critical reflection is said to be a process whereby a person intentionally construes new meanings as a result of examining their own beliefs. It is presented as a process that can occur in many different ways. The theory describes three main frames for critical reflection (Mezirow, 1991, 2000): content reflection, where the data content is considered more deeply for its veracity; process reflection, where the systems that produced the data are held up to scrutiny; and premise reflection, which is reflection on underlying premises, beliefs, and assumptions. Rational discourse is presented in the theory as a form of discussion with other people, focusing on personally and socially held beliefs and assumptions, and conducted in a logical and objective manner, to highlight any incongruencies, biases, or blind spots in those 
beliefs and assumptions, thus allowing them to be addressed.

Based on patterns of activities or behaviour that the participants in Mezirow's (Marsick \& Mezirow, 1978) original study reportedly went through and related, there are 10 recognised steps in the transformative learning process (Marsick \& Mezirow, 1978; Mezirow, 1991, 2012): a disorienting dilemma; self-examination, with feelings of fear, anger, guilt or shame; a critical assessment of assumptions; recognition that one's discontent and the process of transformation are shared; exploration of options for new roles, relationships, and actions; planning a course of action; acquiring knowledge and skills for implementing one's plan; provisional trying of new roles; building competence and self-confidence in new roles and relationships; and a reintegration into one's life on the basis of conditions dictated by one's new perspectives. These ten steps were set out in the original explication of the theory and have changed little since.

The beginnings of the theory are arguably in Mezirow's (1971, p. 135) argument for using grounded theory in 'the systematic construction of an evolving and integrated body of inductively formulated generalizations by which the behaviour of adults in educational situations may be understood and predicted', and in his notion of perspectives as '...people's actions and statements of the ideas that go with these actions' (Mezirow, 1971, p. 145). The theory then emerged as perspective transformation, with Mezirow (1978, p. 100) also suggesting that it was part of an 'emerging transformation theory', developed by using a grounded theory methodology. Mezirow was thus the main initial developer of the theory. He suggested that the recognition of perspective transformation, combined with selfdirectedness, formed 'the essential elements of a comprehensive theory of adult learning and education' (Mezirow, 1981, p.22). He further developed his own 
interpretations of Habermas's ideas (Mezirow, 1985) in his Fostering Critical Reflection in Adulthood (Mezirow, 1990), culminating in his book on transformative learning, where the theory had its first full explication (Mezirow, 1991). There he noted that those who can name 'what is' (p. 3) in new ways, and can influence others to follow that naming, acquire power, or in this case influence. The initial explication of the theory arguably named 'what is' for a variety of educationalists, which for many has become the main adult learning theory of the day, allowing the investigation of new relationships, questions, and things to study (Cranton and Taylor, 2012).

\section{Critical evaluation of the theory to date}

Published critiques of the theory from different perspectives have appeared from the time of its initial articulation. There have been four main types of critical response to the theory. Criticisms of the first type do not cast doubt on the veracity of the theory, but rather suggests that there are certain elements lacking, or requiring further elucidation, in order to improve it. Such criticisms argue that the theory is 'good' and would be 'better', if the points of concern were adequately accounted for. Criticisms of how the theory has dealt with context, relationships and affect may be fitted into this group (Baumgartner, 2012; Cranton and Taylor 2012; Taylor, 1997, 2007, 2011). While these criticisms have in fact contributed to the removal of some of the theory's minor deficiencies, extending its intellectual reach, they cannot be considered criticisms of the fundamentals of the theory in any substantive manner. Within this type of criticism is Taylor and Cranton's perception of a lack of fundamental research into the theory's underpinnings (Cranton and Taylor, 2012; Taylor, 1997, 2007, 2011). In that vein, Taylor (1997) cautioned that, because there might be as yet undetermined possible inadequacies 
in the theory, its application might lead to flawed conclusions.

Criticisms of the second type are those that can be considered 'chicken or egg' arguments: arguments that suffer from a circular causality dilemma, in which it is futile to argue whether one event comes before another. Included here are the criticisms of Collard and Law, who saw the theory as lacking a coherent, comprehensive theory of social change (Collard and Law, 1989, p. 102), a point which is implicitly supported by others, such as Clark and Wilson (1991), and Inglis (1997, 1998). Also in this category is Merriam's (2004) suggestion that a person must have a high enough level of cognitive functioning to engage in rational discourse and to critically reflect on, or otherwise engage in, transformative learning, and Collard and Law's (1989) contention that ideal critical reflection is never really possible because of contingent variables, and that the theory is thus deficient. Against that point, Mezirow $(1989,2000)$ suggested that critical reflection varies (depending on contingent variables), is never ideal, but can, nonetheless, contribute to transformative learning. In this case, Mezirow, and Collard and Law, are falling into the circular causality trap.

Criticisms of the third type are those that involve a rejection of the theory from a conflicting philosophical standpoint. In this category, Pietrykowski (1996) and Clark and Wilson (1991) have argued that Mezirow's theory of transformative learning is too modernist and emancipationist. Given that Mezirow has a stated orientation as an emancipationist, the argument then becomes an argument for-oragainst an emancipationist viewpoint, and is a difference of philosophical standpoints, rather than a coming to terms with the substance of the theory itself (Mezirow, 2000). Another example here is Collard and Law's (1989) and Hart's 
(1990) criticism of the theory on the grounds of its lacking a well-developed and explicit concept of power. Newman (2012) was critical of transformative learning for a variety of reasons, which fall into this final grouping. The arguments presented are well crafted but we would argue that Newman's developed points do not go far enough. Newman's principal argument is that, what is described as transformative learning is really just good learning, any opposition to which is essentially a substantive philosophical matter. Rather than a rejection of the theory as not adding anything to learning, the argument of this paper is that the theory is better understood as a conceptual metaphor. Newman's arguments do, though, point to serious questions about how the adult education community has taken the theory to heart and given it such prominence, when, from the examination of literature undertaken for this analysis, it is arguably inadequately theorized, a quality which, in itself, contributes to the reification of the theory to the level of a universal truth.

Criticisms of the fourth type are those that, while engaging with different aspects or applications of the theory, make small but consequential criticisms that call into question an element of the theory. They appear often as asides to the main argument, for example, that Brookfield (2000) in his comment on the potential meaninglessness of the word transformative, and that of Kokkos (2010) in his pointing out the possible divergence of academic views of the theory's 'components and its methods' as part of another argument. Such points are rarely picked up in subsequent articles, but are often telling, and they have importantly informed the critique developed in this paper.

\section{Transformative learning theory as a conceptual metaphor}


Transformation and learning, in colloquial terms, have what can be considered as overlapping meanings. Thus, learning can be seen to have a transformative effect on the learner, and on the learner's life and, likewise, transformation can be said to create, amongst other effects, learning. Because of this, 'transformative' can be mistakenly seen in this context as merely an adjective, used to describe a particular type of learning. Transformative learning however, the most popular cognate form of Transformative Learning Theory, can also be seen as a conceptual metaphor, as a figure of speech connecting different conceptual domains (Lakoff, 1993; Morgan, 1980).

Transformation, as used by Mezirow (Marsick \& Mezirow, 1978; Mezirow, $1978,1991)$, is the conceptual domain of consciousness raising, improving, becoming free from the past, undoing twisted views of the world, raising above self-limitations, being future oriented, becoming enlightened, unfolding spiritually, metaphorically of butterflies emerging, and all this through an inner awakening, creating a stirring of discontent that generates a drive in a person to enlarge their understanding and appreciation of life. In this domain, a person's way of seeing the world can become more 'inclusive, discriminating, reflective, open, and emotionally able to change' (Mezirow, 2012, author's italics). Transformation implies nothing less than 'light on the road to Damascus', a conversion, a recalibration, and re-integration with the world. Transformation, Brookfield (2012, p. 131) writes, is one of the most powerful words in the English language. It is not a mere adjective as it is used in this context.

Learning, on the other hand, is seen as the conceptual domain concerned with the acquisition of skills, knowledge and understanding brought about through a variety of processes, including reading, studying, being taught, teaching others, curriculum development, pedagogy, different ways of taking in, interacting, 
constructing, and assimilating knowledge, improving one's understanding of that knowledge, and social and community advancement through such processes. While learning is, perhaps justifiably, reified, it also contains the mundane, the hard work, the tedium, the assessments, the arguments, the measuring of self against others, the failures as well as the successes. It is quotidian.

Mezirow (Mezirow \& Marsick, 1978, p. 8) noted the irony that the re-entry programs he studied, and from which the theory emerged, had 'transformed the perspectives of hundreds of thousands of women' through consciousness raising classes, yet had never found their way into the literature of adult education. Bringing transformation and learning together created a conceptual framework through the conceptual metaphor of transformative learning that arguably began this process of bringing legitimacy to consciousness-raising in adult education. Mezirow (Mezirow \& Marsick, 1978, p. 55) proposed that the objective of adult education should be fostering movement 'toward a higher level of development on a maturity gradient' through transformative learning experiences that help adults look at the sources of their needs and hence develop behaviour based on the new maturity, rather than focusing on behaviour change from only learning new behaviour on its own.

According to Lakoff and Johnson (1980, p. 455, author's italics) 'The essence of metaphor is understanding and experiencing one kind of thing or experience in terms of another.' A conceptual metaphor is thus defined as one where a target conceptual domain, is overlain with a source conceptual domain (Kövecses, 2010; Lakoff \& Johnson, 2003). Kovecses (2011, p. 4) wrote that a conceptual domain is any coherent organisation of experience. Faulconnier and Turner (2002) suggested that a conceptual metaphor is a conceptual integration created by blending ideas into a blended mental space that leads to new emergent meanings not contained in the 
original inputs. Lakoff and Johnson (1980, p. 455) suggested that our conventional ways of talking about arguments presuppose a metaphor we are hardly ever conscious of. Metaphors are one way that our experience is made more coherent, and according to Lakoff and Johnson (1980, p. 484) a well-framed or novel metaphor has the power of defining reality, which is similar to Mezirow's (1991, p. 3) contention that naming creates reality. Lakoff and Johnson (p. 156) went further in suggesting that conceptual metaphors may be the only way to organize and make coherent certain aspects of our experience that then can create realities for us, which themselves can play a part in constituting a license for policy change and political and economic action. Arguably, transformative learning as a conceptual metaphor has done this.

In this paper, we are arguing that transformation constitutes a specific source domain, which then influences, colours and creates new understandings in the target domain, in this case the domain of learning. Lakoff and Johnson (1980, p. 460) argued that metaphorical structuring in conceptual metaphors is only ever partial and not total. If it were total, one concept would be the other, rather than merely understood in terms of it. This is an interpretation of Newman's (2012) argument, that transformative learning is just learning, involving a total overlap of transformation and learning: transformation being another way of saying learning and learning another way of saying transformation. But, as a metaphor, which is arguably what Mezirow was implying, transformative learning is about revolutionary enlightenment in a person's psyche - neither simply a learning of skills or ideas, nor simply an awakening in some spiritual sense, but an awakening that leads to new learning that otherwise would not have occurred.

There are a number of other terms that are woven throughout the theory, and new ones are frequently being coined, all of which are also arguably metaphors, 
supporting the argument that the theory operates as a conceptual metaphor:

transformative relationships, transformative rationality, transformative context, transformative experience, transformative effects, transformative potential, transformative discourse, and others (Daloz, 2000; Kegan, 2000; Mezirow, 2000; Mezirow, Taylor, and Associates, 2009; Taylor, 2007). In these instances, the source domain of transformation can be seen as being applied repeatedly to different target domains in this conceptually metaphoric manner, cognate to that of transformative learning (Lakoff \& Johnson, 1980).

The theory may thus be seen as capturing the central features of both a parable and an extended metaphor (both areas not generally covered in conceptual metaphor theory). A parable is being seen here as a short allegorical, yet familiar, story told to illustrate a moral, ethical or teaching point, such as the stories of the New Testament Bible described as being told by Jesus, and Aesop's Fables. An extended metaphor has been described by Pillar (1999) as a metaphor that is consciously sustained throughout a text or discourse, such as Shakespeare's $18^{\text {th }}$ Sonnet, 'Shall I compare thee to a summers day' and, from 'As You Like It', 'All the world's a stage and men and women merely players', both of which continue the metaphor throughout the work or for an extended period. The exact metaphorical designation of the theory is beyond the scope of this paper. However, it can be seen that the theory, through the ongoing nature of the source domain, transformation, being applied to more and more aspects of learning, is also operating as a hybrid of extended and conceptual metaphors, indicated by its inclusion in such a sustained and ongoing manner as the central story in many conferences, books and journals.

\section{Arguments for the theory as a metaphor}

Transformative Learning Theory has not only proven to have great staying power as 
an idea, but also to be a prolific producer of offshoots and closely related ideas (Mezirow and Associates, 2000; Mezirow, Taylor, and Associates, 2009), in spite of the fact that there are deficiencies in its application and perhaps in the theory itself (Taylor, 1997, 2009). There is a raft of small but consequential and unanswerable questions problematising the theory, which have been raised by a variety of theorists in many critiques. By treating the theory as a conceptual metaphor, these many inconsistencies - together with the fact that they are largely ignored when they are raised, and the theory's continued popularity among educational practitioners - not only make sense, but actually serve to unify the theory.

The interwoven problematic areas of the theory that constitute arguments for interpreting it as a metaphor are those of: its unidirectional theorising, its lack of critiquing of the theory in the literature, the failure to validate it, its lack of quantifiability, the problematic nature of its exemplary cases, the failure of elements such as the disorienting dilemma to contribute effectively to it, its lack of predictiveness, its selective attention to research outcomes, an uncritical acceptance of its theoretical solidity, terminological meaninglessness, theoretical unboundedness, and its colonisation of other adult learning concepts. These arguments are articulated and exemplified in the following sub-sections.

\section{Unidirectional theorising}

The unidirectional nature of theorising sees the theory as having led to new applications and theorisations of forms of learning, but with little or no impact on the theory itself (Cranton and Taylor, 2012). Instead, the theory has tended to be kept much as originally stated, but with a diffusion of meaning evidenced by increasingly ambiguous language, and the heightened use of theory jargon, rendering the theory increasingly metaphorical. For instance, in Mezirow's (1991) early articulation, a 
frame of reference and a meaning perspective were treated synonymously, with each being used to illuminate the other. Eighteen years later, Mezirow wrote that frames of reference were structures on which our expectations of and assumptions about our thoughts, feeling and actions were based (Mezirow, 2009, p. 22). He also added that they may be, 'rules, criteria, codes, language, schemata, cultural canon, ideology, standards, or paradigms' and may also include, 'personality traits and dispositions, genealogy, power allocation, worldviews, religious doctrine, aesthetic values, social movements, psychological schema or scripts, learning styles, and preferences’ (Mezirow, 2009, p. 22). It is thus important to note that a frame of reference may also be, 'a predisposition with cognitive, affective, and conative (striving) dimensions' (Mezirow, 2009, p. 22). It is hard to avoid the conclusion that a frame of reference might be almost any aspect of a person's identity, and that any change in it may constitute a transformation. Indeed, Mezirow (2009, p. 23) also claimed that 'transformative learning may be understood as the epistemology of how adults learn to reason for themselves', which is a striking generalisation, as it defines all adult learning that impacts on reasoning as transformative learning. This universalisability of the concept has been underlined by generalizations, such as those of Kasl and Elias (2000), who wrote that transformation, in the theory, is the expansion of consciousness in any human system, collective as well as individual. These examples provide support for the theory being a conceptual metaphor, which permits such generalizations or extensions.

\section{Lack of critique}

That there is a lack of critiquing of the literature on Transformative Learning Theory in the literature has been pointed out repeatedly by Taylor (1997, 2000a, 2007), and Taylor and Snyder (2012), who have made the point that much writing on the theory, 
apart from being redundant, does not build on, critique, or otherwise challenge other writing in the community of transformative learning theorists. While Taylor has noted this point, and has done so more than once, he has avoided speculation as to why this might be so, and why there has been such a lack of attention to his raising the issue in the first place. While the work of Kucukaydin and Cranton (2012) does provide an example of a critique of others' writing, it focuses not on the theory, but on certain writers' attempts to include the extrarational approach ${ }^{3}$ into the theory. While Kokkos (2010, p. 156) has observed that there is a convergence amongst scholars of the theory that the conscious and the unconscious dimensions of learning are important, he has also pointed out that they also have different views on the theory's 'components and its methods'. Unfortunately, he continues the article in an entirely other direction, leaving what is arguably a challengingly bold statement, entirely unaddressed. And Stevens-Long, Schapiro, and McClintock (2012) have pointed to the muddied nature of the way the language is used differently by different researchers and practitioners. After a 30-year exposure to the theory, and after its being considered the new andragogy, the tardy response of transformative learning theorists to such selfgenerated issues, points to the theory being a conceptual metaphor.

\section{Failure to validate}

The failure to validate the theory has also been noted by Cranton and Taylor (2012), who have pointed out the lack of substantive knowledge of the theory's impact on grades, test scores, or performance. Taylor (2000b, p. 16) had already noted that, 'despite all the rhetoric on promoting transformative learning in the adult education classroom, there is little research about its impact on learner outcomes'. The main

\footnotetext{
3 The extrarational approach is here aligned with Jungian depth psychology, and relates to the areas of feeling, imagination, intuition, and dreams (Kucukaydin \& Cranton, 2012).
} 
research focus in the theory over the last two decades has remained one of using qualitative research methodologies to show that transformative learning of one type or another has occurred (Cranton and Taylor, 2012; Taylor, 1997, 2007; Taylor and Snyder, 2012). This focus has produced numerous data sets for which one explanation has been given: an explanation which has been generalized to the status of an adult learning theory. The sheer volume of the data suggests that the theory has been verified, but in reality, the data have been sought through the self-confirming framework of the theory. As Taylor and Snyder (2012, p. 42) have noted:

There was a lack of theoretical analysis of the findings affirming or questioning the underlying assumptions found in the theoretical framework. Instead there is a tendency to be too deterministic where the data seems to fit easily, and to be unquestionably supportive of the theoretical framework, particularly Mezirow's orientation.

As a conceptual, metaphor the theory does not require validation, nor does it create the conditions to bring about a drive to provide more than face validity.

\section{Lack of quantifiability}

The lack of quantifiability of the theory has been noted by Cohen and Piper (2000, p. 208) who, while writing about the neglected role of environment and other nonrational elements that can drive a transformative learning process, mention that 'we can't precisely measure the transformative learning we have witnessed...', but they comment no further on this lack of quantifiability. It is an important lack, because it leaves the theory subject to the vagaries and subjectivities of researchers and research participants in determinations of whether or not a transformative learning experience has occurred. That agreed measures have not been developed points to a problem with 
the theory, as does the lack of discussion of this failure. The lack of measures, let alone agreed measures, means that it is impracticable to discern either the similarities or the differences between the findings of different researchers. Merriam and Kin (2012, p. 58) have pointed out that there are 'only a few studies of transformational learning that have attempted to measure a change in perspective.' Brock (2010), while attempting to measure the outcomes of each of the 10 steps in the theory, showed that the longer students were in the institution she targeted for her research, the more transformative learning they supposedly experienced. Thus, the longer Brock's participating students were in the institution, the more they learned, which is unexceptional, and this as much as anything provides further support for Newman's (2012) contention that transformative learning is nothing more or less than learning. Indeed, Cranton and Taylor (2012, p. 568) have suggested that, due to the overwhelmingly qualitative nature of much of the research into the theory, it could be time to develop some empirically validated sound quantitative survey instruments for the assessment of the process of transformative learning and the outcome of the process. This lack of agreed measures and, until recently, a lack of acknowledgement of the significance of this lack, is another argument that points to the theory being a conceptual metaphor.

\section{Problematic exemplary cases}

The problematic nature of exemplary cases has not been acknowledged in the literature to date. Cranton and Taylor (2012, p. 15) have pointed out that there are some reported outcomes from the application of the theory. However, the works to which they refer highlight a further series of minor, yet unaddressed, problems with the theory. For instance, Donaldson (2009, p. 75), the first source cited in the article by Cranton and Taylor just mentioned, suggests that 'transformative learning begets 
transformative learning' and his writing suggests that deepening understanding is synonymous with transformative learning. This is problematic because it is so general and broad as to be meaningless and, if left to stand unaddressed, implies firstly that transformative learning is as simple as deepening understanding and, secondly, that another precursor for transformative learning is now transformative learning itself, which undermines any empirical purchase of the theory, as it is only self-referential and recursive. Unless it is treated as a purely metaphorical observation, it is problematic. In Cranton and Taylor's second source in which transformative learning outcomes are reported, Easton, Monkman, and Miles (2009, p. 234) describe participants as clearly having 'transformed their lives in the process', although 'It is more difficult to identify just what measures and methods are most directly transformative in the program.' This lack of capacity to identify what transforms is problematic and representative of much of the research, in which outcomes are purported to be transformative while the causal mechanisms remain unarticulated and unclear. In the third example, Cranton and Taylor, Macleod and Egan (2009, p. 119) refer to transformative processes that may or may not be successful in bringing about any transformative learning in their students, some of whom described feelings of threat, discomfort and alienation. The mechanisms that may be at play are unarticulated. These are problematic examples of the theory in action, rather than exemplary ones, and they point to the metaphorical nature of the theory.

\section{Elemental failures}

The failure of elements such as the disorienting dilemma to contribute effectively to the theory is grounded in the reality that the 10 steps developed for the theory are themselves somewhat metaphorical. Mezirow's (Mezirow \& Marsick, 1978) account of the 10 steps acknowledges them as more of a description of praxis than theory. The 
disorienting dilemma, then, as a construct, is problematic, because the nature of dilemmas is treated differently by different theorists, with so little commonality as to render the concept almost meaningless. Daloz (2000), for instance, reported that he had found little evidence for other than incremental transformative changes, and he practically did away with the need for disorienting dilemmas by downgrading them to moment-to-moment life challenges. Taylor (2000a) has pointed out that, despite the research activity, there is a lack of theoretical understanding as to why some disorienting dilemmas lead to transformations and others do not, and Alhadeff-Jones (2012), drawing on Taylor's comments, has suggested that the whole notion of linear causality in the theory, such as a first step being the disorienting dilemma, is flawed. Cranton and Wright (2008) have suggested that a disorienting dilemma may be no more than an activating event that leads a person to engage in further training, which, due to the skills of the teachers, keeps and holds the learners' attention until he or she ends up with a transformative learning experience. It can be argued that the disorienting dilemma has been watered down to include almost any life event. The argument appears to be that the disorienting dilemma is real because a student is required to take on a world view that is different from their own and hence they are

disoriented. However, given that this is a central purpose of education, it is difficult to see how, in the spirit of the theory, it can seriously be seen as a disorienting dilemma or anything other than good teaching or learning, as Newman (2012) has asserted. This is further indication that the theory is operating as a conceptual metaphor, as these discrepancies appear to raise no concerns.

\section{Lack of predictiveness}

The lack of predictiveness of the theory may be a function of its descriptively grounded development. Grounded theory is a methodology intended to create a theory 
to fit a specific selection of data (Chamaz, 2006). The newly created theory, ideally, thus descriptively fits that specific selection of data. We can, theoretically, have confidence that the theory at least fits those data, but we have no grounds for generalisation beyond them. Repeated descriptive research studies confirm, over and over again, the descriptive veracity of the theory, but they contribute nothing to its explanatory or predictive power. The desire to confirm the descriptive utility of the theory in all research situations denies any opportunity to sharpen it to the point that it has any explanatory or predictive power since, to achieve such power, entails a denial of the unbounded interpretation of its key concepts. The theory thus denies any possibility that it could be used to make predictions about the world or to guide educational practise in any empirically-informed manner (Schafersman, 1997). Cranton and Taylor (2012, p. 15) have pointed out that little is known about the impact of transformative learning in the traditional area of formal education: grades, test scores, and performance. The argument here suggests that this is entirely to be expected, since that impact is unknowable, given the theory's lack of predictiveness. It is further evidence of the purely metaphorical nature of the theory.

\section{Selective attention to research outcomes}

The selective attention to research outcomes may be seen as ensuring the perpetuation of the theory's weaknesses. For instance, there is a lack of replicability of the disorienting dilemma as a reliable kick-start to the transformative learning process (Taylor, 2000a). Apparently, a disorienting dilemma does, on occasion, kick-start the process described by the theory but, on other occasions, it does not. This suggests that there are elements in transformative learning for which the theory cannot account. And not only are those elements unaccounted for, but they are of significance, and they remain unacknowledged. A theory that relies on cherry-picking the positive 
research responses that fit its view of the world is problematic. Along with the lack of response to this conceptual problem, alternative understandings have not been sought for the same data. In the literature on transformative learning theory, there is no acknowledgement, investigation, or consideration of similar experiences not gained through the processes elucidated in the theory. Neither is there any acknowledgement of experiences of perspective transformations that have not been positive, expansive, creative of flexibility, and so on. It may be suggested in this regard that published research on the theory fits into a one of four categories: (1) that which produces data that can be described as fitting into the theory or approximate versions of it; (2) that which supposedly further explicates elements of the theory (such as what is a meaning perspective? (Cranton and Taylor, 2012); (3) that which combines elements of the theory, either in part or in total, with other models of learning or human functioning (e.g., transformative learning and Jungian depth psychology in Dirkx, 2001, 2012); and (4) that which uses the theory to stretch the boundaries of what otherwise might not be considered either learning or legitimate research into adult learning (Tisdall, 2009). Thus far, there has appeared little research that considers such questions as What else could be happening? Why does it appear to work for one person and not another? Why is it not replicable? What is this disorienting dilemma? and What is it that is taking place here? In short, the selective use of research to confirm the theory points to its functioning as a conceptual metaphor.

\section{Uncritical acceptance of theoretical solidity}

The uncritical acceptance of the theory's theoretical solidity has become increasingly apparent over time. Returning to the methodological limitations of the grounded theory approach to the theory's formulation, Glaser and Strauss (1967) have argued that grounded theory may lead to the discovery of new theory, and this is certainly 
how this theory is treated by many: as a reality discovered (Chamaz, 2006): as a thing that is out there to be researched, elucidated, explicated, polished, and refined, rather than as an explanatory and predictive interpretation of experiences and phenomena. It thus tends to be seen as a given, from which to view other data and theories (Cranton $\&$ Taylor, 2012). Treating the theory as though it described an existing entity permeates the literature on the subject and lends support to seeing it as a conceptual metaphor. Research grounded in the theory all progresses on the understanding that a transformative learning process exists and that it was discovered, unearthed, described, and clarified in its theorisation. The theory has thus been identified as an objective truth, despite Mezirow (2000, p. 344) being insistent that it was simply the best judgment of people in this field of endeavour, and Kucukaydin and Cranton's (2012, p. 11) suggestion that 'knowledge about transformative learning has been constructed by a community of scholars working to explain how adults experience a deep shift in perspective that leads them to better justified and more open frames of reference.' The uncritical acceptance of the theory's solidity is exemplified by Mälkki (2010, p. 208) who, in using the theory, asserted that it 'has been validated through numerous empirical studies...', giving seven references in support of this claim, none of which is grounded in empirical research that could be said to provide any validation of the theory. Often it appears as though scholars of Transformative Learning Theory are uncritical when using the work of other writers to support their contentions. In this instance, the cumulative lack of causal clarity, or evidence, is yet another feature of the theory, unremarked on by its protagonists, and a further indication of its power as a conceptual metaphor.

\section{Terminological meaninglessness}

The terminological meaninglessness in the theorisation of Transformative Learning 
Theory is consistent with the points already noted. Brookfield (2000, p. 139) lamented the use of the word transformative for any instance of reflection that leads to any modification of assumptions, no matter how trivial, and Tisdell (2012, p. 22) pointed out that it is used by many people as a synonym for any kind of learning. Kegan (2000, p. 47) suggested that the appealing nature of the language leaves it open to being used for a variety of purposes, its meaning becoming distorted, and its distinctive idea becoming lost, to the extent of its taking on quasi-religious qualities. This is an indication of the problematic metaphoric character, in this context, of the word transformative. In this instance, the word is being used as a term to highlight a change, while at the same time trying to imbue it with gravitas and kudos: as nothing less than a transformation (Brookfield, 2012). Kegan (2000, p. 48) has suggested that the there needs to be an epistemological narrowing of the way the term is used, while Brookfield's solution to this problem is to narrow its focus to critical self reflection on assumptions (just one element of the present theory). Others have criticized the theory as being too narrow, or have reported such criticisms by others, because it relies as it does on the centrality of rationality in learning (Cranton, 2000; Mezirow, 2009; Taylor, 1997, 2007), while Belenky and Stanton (2000) have suggested that the theory focuses too narrowly because it does not trace the many steps people take before they know how they know, by focusing just on the endpoint of development. There is no general agreement about what is and what is not transformative learning, or the difference between transformative and other learning. These kinds of limitations are explicable through considering the theory as a conceptual metaphor.

\section{Theoretical unboundedness}

The unboundedness of the theory is evidenced in the continuing multiplication of educational outcomes that are identified as being transformative. We are now faced 
with the situation where any personally significant learning experience or consciousness-raising process, such as learning to become a less conservative person, becoming a more conservative person, turning suddenly vegetarian, or becoming 'green', and such like is argued to be transformative learning. This is done irrespective of whether or not the other aspects of the theory are accounted for, or whether or not there has been any serious analytical investigation of the adequacy of either the theory, or the conceptual overlaps between it and the changes being described to have occurred to individuals (Brookfield, 2000). This unboundedness of the theory contributes further to its raft of unanswered or unanswerable questions (Cranton and Taylor, 2012; Newman, 2012) and argues for its metaphorical nature since, as such, the unboundedness becomes unproblematic.

\section{Colonisation of other concepts}

That unboundedness, effectively allows the theory to colonise a host of other adult learning concepts: processes which, in and of themselves, have been recognised independently of the theory, but which now can be defined as processes that bring about a transformative learning experience. Engagements such as peer reflection and critical reflection thus become subsumed under the rubric of the theory (Brookfield, 2009). Everything that encourages reflection on assumptions becomes part of the theory. It can be argued that researchers are working to tie particular types of adult learning to the transformative learning bandwagon, as for example, in: Adria's (2009) ‘Transformative Learning Through Deliberative Dialogue'; Brendel's (2009) 'Narrative Driven Transformative Learning among Hospice Patients'; and Hunt's (2009) 'Creative Writing as a Tool for Transformative Learning', each author has presented a learning tool as a transformative process. The theory seems to be taking over the adult learning world by stealth and inattentiveness, rather than 
thoughtfulness. It thus becomes the organising framework for a variety of other approaches to adult learning, all of which are assumed to be transformational. When this occurs, the whole theory becomes suspect, because it effectively lacks any real boundaries, and without boundaries, it becomes incoherent and meaningless (Brookfield, 2000; Newman, 2012; Tisdell, 2009), albeit a beautiful metaphor. To quote Taylor and Cranton (2012, p. 17):

Most significantly, its [transformative learning theory's] ubiquitous presence beyond the field of adult education has led to a construct that has come to mean many things to many educators.

\section{Implications of this perspective}

The proposition of the theory being a conceptual metaphor has a number of implications that are considered in this section. For a start, the theory as a conceptual metaphor is fruitful in practise. According to Arbusson, Harrison, and Ritchie (2006), a research and teaching metaphor should allow an imaginative leap between known and unknown ways of thinking that then allows for further planning, thinking, conceiving, research, and action to take place. This has proven to be the case here, with the metaphor facilitating leaps of imagination from previous conceptions of learning, consciousness raising, and what are legitimate areas of adult education, to the idea of transformative learning theory as a new, special, and different arena of adult learning, ripe for further exploration. The conceptual metaphor in this case serves the purpose of generating an image of learning as a transformative experience, which then provides the basis for the research, theorising, and practise that follows.

The theory as a metaphor may also be seen as stimulating academic enquiry and investigation into hitherto unexamined human learning processes relating to 
significant shifts in individuals' conceptions of themselves, the world, and how the world works. Seeing the theory as a conceptual metaphor also stimulates discussion and dialogue. The need to be emphatic about trying to establish the theory as 'real', 'true' or 'valid', is thus rendered inconsequential. In effect, it is frees up the discussions that can be had through the theory. As a metaphor, it can be extended, modified, reformulated, added to, redefined, re-envisioned, and played with to almost any extent, just as can be done with metaphors generally. It is this technical capacity of a metaphor that allows imagination to be used when working with theory construction (Morgan, 1983). This is what appears to have happened in many instances in the ways in which the theory has been applied by researchers and practitioners. Consider for instance, the titles of the following presentations from amongst a wide range of equally diverse presentations from the Eighth and Ninth International Transformational Learning Conferences; they show great invention and creativity by looking at photography, music, contemplative education, ${ }^{4}$ and parenting through the lens of the theory: 'Looking at the World Through Multiple Lenses: Photography as Transformative Learning' (Lawrence and Cranton, 2009), 'Balance on the Water: Jimmy Buffett [the popular musician] as Transformative Philosopher and Guide' (Feller, 2009), 'The Art of Contemplation-Oriented Transformative Facilitation: A Perspective from Thailand' (Nilchaikovit, 2009), and 'Transition to Parenthood: A Qualitative Study Using the Theory of Transformative Learning' (Klobucar, 2011).

As a conceptual metaphor, the theory also lends itself to being applied in a diverse range of contexts that a more rigorous theory might not immediately permit.

4 Contemplative education is 'an education that enable[s] one to truly know one's mind and hence gain wisdom, which means reaching the ultimate truth or reaching the truth the beauty and the good' (Wasi, 2007; as quoted in Nilchaikovit, 2009, p. 290). 
Indeed, it has been applied widely and imaginatively, as the examples given in the paragraph above illustrate. Examples of the broad range of applications (as distinct from the purely imaginative applications) that practitioners are making with the theory can readily be seen in a recent book from Mezirow, Taylor, and Associates (2009). In that book, there are articles on applications of transformative learning to community and social change, such as women's education and work in Bolivia, farming schools in rural West Africa, and the empowerment of women in East Harlem, USA. There are applications to education in corporate America, workplace learning, coaching, developing critical reflection, and in adult basic education. There are applications in higher education to practises such as mentoring, culturally responsive teaching, promoting dialogical teaching in academic faculties, and palliative care education. Looking at the proceedings from conferences also points to a great diffusion of the idea of the theory into diverse areas. This paper makes the argument that this is possible precisely because the theory is a conceptual metaphor, allowing it to be widely applied, in this case, in an inspirational manner.

Treating the theory as a conceptual metaphor also gives insight into the absence of research into the fundamentals of transformative learning, an issue raised earlier in this paper. As a metaphor, the theory serves to stimulate practitioners and researchers to apply it and experiment with it in their practice, and to extend its uses. It reduces or even eliminates altogether the need to undertake fundamental research. The critical faculties that might be brought to bear on a more thorough research-based and peer-assessed theory have been rendered redundant. Consequently, intellectual effort is focused on repeated applications of the theory as a way of explaining changes in adult students, or of preparing ways to interact and teach adult students in a wide variety of situations. Such redundancy of research into transformative learning that 
simply applies the theory to new situations is a natural consequence of its serving as a conceptual metaphor.

Treating the theory as a metaphor also makes sense of it being treated at times as more than a theory, and more like a general truth. Taylor, and others, have identified the paucity of fundamental research into the theory, and the plausible implication that it has become reified (Brookfield, 2000; Cranton and Taylor, 2012; Taylor, 1997, 2007). Considering transformative learning as a conceptual metaphor makes sense of this issue. Arguably, if we are dealing with a metaphor, the better the metaphor, the more it will lend itself to reification and hence uncritical acceptance. Howard (1987) suggests that the more closely the metaphor resembles the lived experience of students, researchers and teachers, the more likely it is to be accepted, as it is, and on its own terms, regardless of informing research or its absence. The face validity of the theory, in reality a conceptual metaphor, tends to overcome concerns about its underlying inadequacy. It reduces the felt need for adequate theoretical exploration and research on the part of practitioners and academics alike.

While Mezirow in each explication of his theory has been substantively true to the original presentation, he has introduced language that itself remains uncontested and undefined. Conceiving transformative learning as a conceptual metaphor renders acceptable this redundant, creative and poetical use of language.

\section{Conclusion}

It has been argued here that Transformative Learning Theory has a telling array of inadequacies as a theory of learning, in spite of which, it has been widely accepted and adopted: an apparent anomaly that is explicable through seeing the theory as a 
conceptual metaphor. Recognising Transformative Learning Theory as a conceptual metaphor, albeit a metaphor masquerading as a theory, has allowed it to be applied and used in a wide variety of settings, while remaining immune to critical inquiry. The notion of Transformative Learning Theory as being essentially metaphorical in nature, may thus be seen as providing an explanation for Newman's (2012, p. 40) telling speculation from his critique that:

This leads me to wonder whether transformative learning only exists in the realm of theory. Perhaps it is a plaything of the mind, about which we can argue the toss, but which has little or no basis in everyday practise.

Michael, it does not even exist in the realm of theory, but as a conceptual metaphor in a manner that theory cannot hope to attain to.

\section{References}

Adria, M. (2009). Transformative learning through deliberative dialogue. In P. Cronton, E. Tayor, and J. Tyler (Eds), Proceedings of the Eighth International Transformative Learning Conference: Reframing social sustainability in a multicultural world (pp. 8-13). Bermuda: Penn State.

Arbusson, P. J., Harrison, A.G., and Ritchie, S. (2006). Metaphor and analogy in science education. Netherlands: Springer.

Alhadeff-Jones, M. (2012). Transformative learning and the challenges of complexity. In E. Taylor, P. Cranton, and Associates (Eds), The Handbook of Transformative Learning: Theory, Research and Practise (pp. 178-194). San Francisco, CA: Jossey-Bass.

Baumgartner, L. M. (2012). Mezirow's theory of transformative learning from 1975 to present. In E. Taylor, P. Cranton, and Associates (Eds), The Handbook of 
Transformative Learning: Theory, Research and Practise (pp. 99-115). San Francisco, CA: Jossey-Bass.

Belenky, M., and Stanton, A. (2000). Inequality, development, and connected knowing. In J. Mezirow, and Associates (Eds), Learning as Transformation: Critical Perspectives on a Theory in Progress (pp. 71-102). San Francisco, CA: Jossey-Bass.

Brendel, W. (2009). Narrative driven transformative learning among hospice patients. In P. Cranton, E. Taylor, and J. Tyler (Eds), Proceedings of the Eighth International Transformative Learning Conference: Reframing social sustainability in a multicultural world (pp. 44-49). Bermuda: Penn State.

Brock, S. (2010). Measuring the importance of precursor steps to transformative learning. Adult Education Quarterly, 60, 122-142.

Brookfield, S. (2000). Transformative learning as ideology critique. In J. Mezirow, and Associates (Eds), Learning as Transformation: Critical Perspectives on a Theory in Progress (pp. 125-148). San Francisco, CA: Jossey-Bass.

Brookfield, S. (2009). Engaging critical reflection in corporate America. In J. Mezirow, E. Taylor, and Associates (Eds), Transformative Learning in Practise: Insights from Community, Workplace, and Higher Education (pp. 125-135). Jossey-Bass, CA: San Francisco.

Chamaz, K. (2006) Constructing grounded theory: A practical guide through qualitative analysis. London, England: Sage.

Clark, M. C., and Wilson, A. L. (1991). Context and rationality in Mezirow's theory of transformational learning. Adult Education Quarterly, 41, 75-91.

Cohen, J., and Piper, D. (2000). Transformation in a residential adult learning 
community. In J. Mezirow (Ed.), The Handbook of Transformative Learning: Theory, Research and Practise (pp. 205-228). San Francisco, CA: JosseyBass.

Collard, S., and Law, M. (1989). The limits of perspective transformation: A critique of Mezirow's theory. Adult Education Quarterly, 39, 99-107.

Cranton, P. (2000). Individual differences and transformative learning. In J. Mezirow (Ed.), The Handbook of Transformative Learning: Theory, Research and Practise (pp. 181-204). San Francisco, CA: Jossey-Bass.

Cranton, P., and Taylor, E. (2012). Transformative learning theory: Seeking a more unified theory. In E. Taylor, P. Cranton, and Associates (Eds), The Handbook of Transformative Learning: Theory, Research and Practise (pp. 3-20). San Francisco, CA: Jossey-Bass.

Cranton, P., and Wright, B. (2008). The transformative educator as learning companion, Journal of Transformative Education, 6, 33-47

Daloz, L. A. P. (2000). Transformative learning for the common good. In J. Mezirow, and Associates (Eds), The Handbook of Transformative Learning: Theory, Research and Practise (pp. 103-124). San Francisco, CA: Jossey-Bass.

Dirkx, J. M. (2001). Images, transformative learning and the work of soul. Adult Learning, 12, 15-16.

Dirkx, J. M. (2012). Nurturing soul work: A Jungian approach to transformative learning. In E. Taylor, P. Cranton, and Associates (Eds), The Handbook of Transformative Learning: Theory, Research and Practise (pp. 116-130). San Francisco, CA: Jossey-Bass.

Donaldson, J. (2009). Fostering transformative learning in leadership development. In 
J. Mezirow, E. Taylor, and Associates (Eds), Transformative Learning in Practise: Insights from Community, Workplace, and Higher Education (pp. 67-77). San Francisco, CA: Jossey-Bass.

Easton, P., Monkman, K., and Miles, R. (2009). Breaking out of the egg: Methods of transformative learning in rural Africa. In J. Mezirow, E. Taylor, and Associates (Eds). Transformative Learning in Practise: Insights from Community, Workplace, and Higher Education (pp. 227-239). Jossey-Bass, CA: San Francisco.

Feller, A. E. (2009). Balance on the water: Jimmy Buffett as transformative philosopher and guide. In P. Cranton, E. Taylor, and J. Tyler (Eds), Proceedings of the Eighth International Transformative Learning Conference: Reframing social sustainability in a multicultural world (pp. 519-521). Bermuda: Penn State.

Gerring, J. (1999). What makes a concept good? A criterial framework for understanding concept formation in the social sciences. Polity, 31, 357-393.

Glaser, B. G. (2002). Conceptualization: On theory and theorizing using grounded theory. International Journal of Qualitative methods, 1, 23-49.

Glaser, B. G., and Strauss, A. L. (1967). The discovery of grounded theory: Strategies for qualitative research. New York, NY: Aldine De Gruyter.

Gunnlaugson, O. (2008). Metatheoretical prospects for the field of transformative learning. Journal of Transformative Education, 6, 124-135.

Habermas, J. (1971). Knowledge and human interests. Boston, MA: Beacon Press.

Hart, M. (1990). Critical theory and beyond: Further perspectives on emancipatory education. Adult Education Quarterly, 40, 125-138. 
Hunt, C. (2009). Creative writing as a tool for transformative learning. In P. Cranton, E. Taylor, and J. Tyler (Eds), Proceedings of the Eighth International Transformative Learning Conference: Reframing social sustainability in a multicultural world (pp. 172-177). Bermuda: Penn State.

Inglis, T, (1997). Empowerment and emancipation. Adult Education Quarterly, 48, 317.

Inglis, T. (1998). A critical realist approach to emancipation: A response to Mezirow. Adult Education Quarterly, 49, 72-76.

Kasl, E., and Elias, D. (2000). Creating new habits of mind in small groups. In J. Mezirow, and Associates (Eds), The Handbook of Transformative Learning: Theory, Research and Practise (pp. 229-252). San Francisco, CA: JosseyBass.

Kegan, J. (2000). What "form" transforms? A constructive-developmental approach to transformative learning. In J. Mezirow, and Associates (Eds), The Handbook of Transformative Learning: Theory, Research and Practise (pp. 35-70). San Francisco, CA: Jossey-Bass.

Klobucar, N. 2011. Transition to parenthood: A qualitative study using the theory of transformative learning. In M. Alhadeff-Jones, and A. Kokkos (Eds), Proceedings of the 9th International Transformative Learning Conference: Transformative Learning in Time of Crisis: Individual and Collective Challenges. New York \& Athens: Teachers College, Columbia University \& The Hellenic Open University.

Knowles, M. S. (1970). The modern practise of adult education: Andragogy versus pedagogy. Chicago: Association Press. 
Kokkos, A. (2010). Transformative learning through aesthetic experience: Towards a comprehensive method. Journal of Transformative Education, 8, 155-177.

Kövecses, Z. (2010). Metaphor: A practical introduction. Oxford University Press: Oxford.

Kucukaydin, I., and Cranton, P. (2012). Critically questioning the discourse of transformative learning theory. Adult Education Quarterly 63, 43-56.

Lakoff, G. (1993). Contemporary theory of metaphor. In A. Ortony (Ed.), Metaphor and thought (pp. 202-251). New York: Cambridge University Press.

Lakoff, G., and Johnson, M. (1980). Conceptual metaphor in everyday language. The Journal of Philosophy, 77, 453-486.

Lakoff, G., and Johnson, M. (2003). Metaphors we live by. Chicago: University of Chicago Press

Lawrence, L. R., and Cranton, P. (2009). Looking at the world through multiple lenses: Photography as transformative learning. In P. Cranton, E. Taylor, and J. Tyler (Eds), Proceedings of the Eighth International Transformative Learning Conference: Reframing social sustainability in a multicultural world (pp. 456-461). Bermuda: Penn State.

Macleod, R., and Egan, T. (2009). Transformative palliative care education. In J. Mezirow, E. Taylor, and Associates (Eds), Transformative Learning in Practise: Insights from Community, Workplace, and Higher Education (pp. 111-122).

Mälkki, K. (2010). Rethinking disorienting dilemmas within real-life crises: The role of reflection in negotiating emotionally chaotic experiences. Adult Education Quarterly, 62, 207-229. 
Merriam, S. B. (2004). The role of cognitive development in Mezirow's transformational learning theory. Adult Education Quarterly, 55, 60-68.

Merriam, S. B., and Kin, S. (2012). Studying transformative learning: What methodology? In E. Taylor, and P. Cranton (Eds), The handbook of transformative learning: Theory, research and practise (pp. 56-72). San Francisco, CA: Jossey-Bass.

Mezirow, J. (1971). Toward a theory of practice. Adult Education, 21, 135-147.

Mezirow, J. (1978). Perspective transformation. Adult Education, 28, 100-110.

Mezirow, J. (1981). A critical theory of adult learning and education. Adult Education, 32, 3-24.

Mezirow, J. (1985). Concept and action in adult education. Adult Education Quarterly, 35, 142-151.

Mezirow, J. (1990). Fostering critical reflection in adulthood: A guide to transformative and emancipatory learning. San Francisco: Jossey-Bass Publishers.

Mezirow, J. (1991). Transformative dimensions of adult learning. San Francisco, CA: Jossey-Bass.

Mezirow, J. (2000). Learning to think like an adult. Core concepts of transformation theory. In J. Mezirow, and Associates (Eds), The Handbook of Transformative Learning: Theory, Research and Practise (pp. 35-70). San Francisco, CA: Jossey-Bass.

Mezirow, J. (2009). Transformative learning theory. In J. Mezirow, and E. W. Taylor (Eds), Transformative Learning in Practise: Insights from Community, 
Workplace, and Higher Education (pp. 18-32). San Francisco, CA: Jossey Bass.

Mezirow, J. (2012). Learning to think like an adult: Core concepts of transformation theory. In E. Taylor, and P. Cranton (Eds), The Handbook of Transformative Learning: Theory, Research and Practise (pp. 73-96). San Francisco, CA: Jossey-Bass.

Mezirow, J., and Associates. (2000). The Handbook of Transformative Learning: Theory, Research and Practise. San Francisco, CA: Jossey-Bass.

Mezirow, J., and Marsick, V. (1978). Education for perspective transformation: Women's re-entry programs in community college. New York, NY: Teachers College, Columbia University.

Morgan, G. (1980). Paradigms, metaphors, and puzzle solving in organization theory. Administrative Science Quarterly, 25, 605-622.

Morgan, G. (1983). More on metaphor: Why we control tropes in administrative science. Administrative Science Quarterly, 28, 601-607.

Newman, M. (2012). Calling transformative learning into question: Some mutinous thoughts. Adult Education Quarterly, 62, 36 - 55.

Nilchaikovit, T. (2009). The art of contemplation-oriented transformative facilitation: A perspective from Thailand. In P. Cranton, E. Taylor, and J. Tyler (Eds), Proceedings of the Eighth International Transformative Learning Conference: Reframing social sustainability in a multicultural world (pp. 290-294). Bermuda: Penn State.

Pietrykowski, B. (1996). Knowledge and power in adult education: Beyond Freire and Habermas. Adult Education Quarterly, 46, 82-97. 
Pillar, I. (1999). Extended metaphor in automobile fan discourse. Poetics Today, 20, 483-498.

Schafersman, S. D. (1997). An introduction to science, scientific thinking and the scientific method. Retrieved from http://www.geo.sunysb.edu/esp/files/scientific-method.html (accessed 20 June 2012)

Stevens-Long, J., Schapiro, S. A., and McClintock, C. (2012). Passionate scholars: Transformative learning in doctoral education. Adult Education Quarterly, 62, $180-198$.

Taylor, E. (1997). Building upon the theoretical debate: A critical review of the empirical studies of Mezirow's transformative learning theory. Adult Education Quarterly, 48, 34-59.

Taylor, E. (2000a). Analyzing research on transformational learning theory. In J. Mezirow, and Associates (Eds), The Handbook of Transformative Learning: Theory, Research and Practise (pp. 35-70). San Francisco, CA: Jossey-Bass.

Taylor, E. (2000b). Fostering Mezirow's transformative learning theory in the adult education classroom: A critical review. The Canadian Journal for the Study of Adult Education, 14, 1-28.

Taylor, E. (2007). An update of transformative learning theory: A critical review of the empirical research (1999-2005). International Journal of Lifelong Education, 26, 173-191.

Taylor, E. (2009). Fostering transformative learning. In J. Mezirow, and E. W. Taylor (Eds). Transformative learning in practise: Insights from community, workplace, and higher education (pp. 3-17). San Francisco, CA: Jossey Bass. 
Taylor, E. (2011). Transformative learning theory: Review of research 2006-2011. In M. Alhadeff-Jones, and A. Kokkos (Eds), Transformative learning in time of crisis: Individual and collective challenges: Proceedings of the 9th International Transformative Learning Conference. New York, NY \& Athens, Greece: Teachers College, Columbia University \& The Hellenic Open University.

Taylor, E., Cranton, P., and Associates. (2012). The Handbook of Transformative Learning: Theory, Research and Practise. San Francisco, CA: Jossey-Bass.

Taylor, E., and Cranton, P. (2012). Reflecting back and looking forward. In E. Taylor, and P. Cranton (Eds), The Handbook of Transformative Learning: Theory, Research and Practise (pp. 73-96). San Francisco, CA: Jossey-Bass.

Taylor, E., and Snyder, M. (2012). A critical review of research on transformative learning theory, 2006-2012. In E. Taylor, and P. Cranton (Eds), The Handbook of Transformative Learning: Theory, Research and Practise (pp. 73-96). San Francisco, CA: Jossey-Bass.

Tisdell. E. J. (2009). Transformative learning, culture, and emerging wisdom in research across borders about spiritual development. In P. Cranton, E. Taylor, and J. Tyler (Eds), Proceedings of the Eighth International Transformative Learning Conference: Reframing social sustainability in a multicultural world (pp. 519-521). Bermuda: Penn State.

Turner, M., and Fauconnier, G. (2002). Metaphor, metonymy, and binding. In R. Dirvan \& R. Porings (Eds.), Metaphor and metanomy in compare and contrast (pp. 469-487). The Hague: Mouton de Gruyter.

Washburn, A. M. (2008). An empiricist's musings about reality, evidence, and data: 
Accumulating support for transformative learning. Journal of Transformative Education, 6, 155-158. 